\title{
Favorable Prognosis of Wheat Allergy in Adults
}

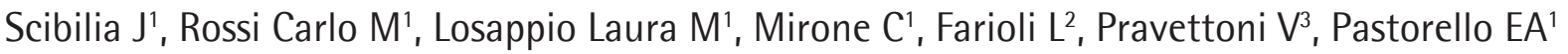 \\ 'Unit of Allergology and Immunology, Dipartimento Medico Polispecialistico, ASST Grande Ospedale Metropolitano Niguarda, Milan, Italy \\ ${ }^{2}$ Department of Laboratory Medicine, ASST Grande Ospedale Metropolitano Niguarda, Milan, Italy \\ ${ }^{3}$ Clinical Allergy and Immunology Unit, Foundation IRCCS Ca' Granda, Ospedale Maggiore Policlinico, Milan, Italy
}

J Investig Allergol Clin Immunol 2019; Vol. 29(2): 118-123

doi: 10.18176/jiaci.0296

\begin{abstract}
Background: Wheat ingestion can lead to disorders such as IgE-mediated food allergy and wheat-dependent exercise-induced anaphylaxis (WDEIA), both of which are associated with impaired quality of life and significant morbidity. Allergy to wheat is relatively benign in children, although its natural history in adults is still unknown.

Objective: We used placebo-controlled challenge to evaluate the natural history of wheat hypersensitivity in atopic patients with adultonset wheat allergy.

Methods: We enrolled 13 patients from an initial cohort of adult patients with IgE-mediated wheat allergy (mean age, 40 years). After diagnosis, the patients observed a wheat-free diet and were followed as outpatients for 5 years to evaluate wheat exposure. Wheat-lgE titers were determined at the end of follow-up, and a second wheat-challenge was performed.

Results: Ten out of 13 patients took part in the study. The mean period of wheat avoidance was 4.2 years. Three patients had spontaneously reintroduced wheat before the second evaluation, after a mean (IQR) of 28 (18-36) months, with only mild gastrointestinal discomfort at reintroduction. At the end of follow-up, 9 of the 10 patients were wheat-tolerant. Two patients had a history of WDEIA. We observed a reduction in IgE levels, with median (IQR) IgE falling from $2.77(0.35-100) \mathrm{kU} / \mathrm{L}$ at diagnosis to $0.88(0.1-20.8) \mathrm{kU} / \mathrm{L}$. The association between $\lg E$ and a negative challenge result was not statistically significant.

Conclusion: IgE-mediated wheat allergy in adults is benign and represents a temporary break in gastrointestinal tolerance. Future studies may improve our knowledge of wheat allergens, routes of and factors leading to sensitization, and prognostic biomarkers.

Key words: Wheat allergy. Adult food allergy. Food tolerance. Double-blind placebo-controlled food challenge.
\end{abstract}

\section{Resumen}

Introducción: La ingesta de trigo puede originar varias patologías como alergia alimentaria mediada por IgE y la anafilaxia inducida por ejercicio previa ingesta de trigo. Todas ellas originan un descenso en la calidad de vida y una importante morbilidad. La alergia a trigo es relativamente benigna en niños, sin embargo, su historia natural en adultos es aún desconocida.

Objetivo: Evaluamos la historia natural de la hipersensibilidad al trigo de inicio en la edad adulta en pacientes atópicos confirmado mediante pruebas de exposición oral.

Métodos: Se incluyeron 13 pacientes de una cohorte de pacientes adultos (edad media 40 años) con alergia a trigo mediada por lgE. Tras el diagnóstico los pacientes siguieron una dieta exenta de trigo y fueron seguidos durante 5 años para valorar su tolerancia tras la exposición al trigo. Al final del seguimiento se determinaron los valores de lgE específica a trigo y se realizó una segunda provocación oral con trigo. Resultados: 10 de los 13 pacientes tomaron parte en el estudio. La duración media del periodo de no ingesta de trigo fue de 4,2 años. 3 pacientes reintrodujeron por iniciativa propia la ingesta de trigo antes de la segunda evaluación, después de un periodo medio de 28 meses (RIQ 18-36 meses), presentando solo leves síntomas gastrointestinales. Al final del seguimiento, 9/10 pacientes toleraron la ingesta de trigo. 2 pacientes tenían historia de anafilaxia inducida por ejercicio. Se observó una disminución de los valores de lgE específica desde una mediana de 2,77 kU/l (RIQ 0,35-100 kU/L) en el momento del diagnóstico hasta 0,88 kU/l (RIQ 0,1-20,8 Ku/L) al final del seguimiento. No se observó correlación entre los valores de lgE específica y los resultados de la tolerancia final.

Conclusión: La alergia a trigo mediada por lgE en adultos es una patología benigna y representa una interrupción temporal de la tolerancia gastrointestinal. Futuros estudios podrían mejorar nuestro conocimiento sobre los alérgenos del trigo, rutas y factores que llevan a la sensibilización, y biomarcadores de pronóstico.

Palabras clave: Alergia a trigo. Alergia alimentaria en el adulto. Intolerancia alimentaria. Provocación alimentaria doble ciego con placebo control. 


\section{Introduction}

Wheat is one the most widely cultivated cereals owing to its easy growth and resistance to environmental stresses. In addition, its high nutritional value makes it the basis of diets worldwide. As a result, it is not surprising that consumption has been associated with a wide array of disorders that, on the basis of individual atopic background, may be IgE-mediated, cell-mediated, or both.

Classic food allergy and wheat-dependent exerciseinduced anaphylaxis (WDEIA) are IgE-mediated forms of disorders brought on by wheat ingestion, whereas baker's asthma is caused by protein inhalation. Moreover, wheat protein contact urticaria is caused by skin exposure, and an IgE-mediated reaction has been observed in persons sensitized to Glupearl 19S, a wheat hydrolyzed protein present in soaps [1].

Cell-mediated reactions include celiac disease and dermatitis herpetiformis, which have been described as autoimmune disorders. Interest has recently grown in the so-called nonceliac gluten sensitivity, where gluten exerts its pathogenic role via an as yet unknown mechanism, and irritable bowel syndrome, where fermentable wheat carbohydrates may significantly worsen the clinical picture.

The prevalence of IgE-mediated wheat allergy in pediatric populations varies from $0.5 \%$ to $1 \%$, as demonstrated in double-blind placebo-controlled food challenge (DBPCFC) studies published in the USA and Europe [2,3]. Moreover, wheat allergy seems to be more frequent in areas such as Japan and other eastern countries - the reasons for this finding remain unclear-as well as in northern Europe, where wheat is the most relevant cause of WDEIA.

Wheat allergy is rarer in adults. It is conceivable that wheat, with its peculiar physico-chemical features, immunogenic peptides, and various routes of sensitization, can induce a break in oral tolerance in a subset of atopic adult patients. In a previous study, we described a series of atopic patients with adult-onset IgE-mediated wheat allergy that was assessed using DBPCFC [4].

It is interesting to note that while most children outgrow food allergy to milk and egg in adolescence and rarely outgrow allergy to nuts, the case of wheat allergy seems to stand between these 2 extremes, with almost half of patients becoming tolerant by the age of 8 years [5]. Moreover, pediatric patients with high titers of wheat-specific $\operatorname{IgE}$ and more severe clinical manifestations of wheat allergy have shown less favorable outcomes and more delayed development of wheat tolerance [4-6]. In children, however, avoidance is not the only approach, and active intervention with oral immunotherapy has recently been reported [6] In a cohort of 6 patients sensitized to $\alpha$-amylase inhibitors, rapid tolerance was safely achieved in 5 patients $(83 \%)$ with only a minority of doses $(6.25 \%)$ and was associated with mild adverse reactions in the up-dosing phase. Data on the natural history of allergy to wheat in adult patients is lacking. The aim of this study, therefore, was to analyze the outcome of wheat allergy through a prospective follow-up study of a previously described cohort of patients with adult-onset wheat allergy [4]. Indeed, we believe that knowledge of the natural history of wheat allergy in adults has significant and possibly divergent implications for therapy in patients with food allergy: a wait-and-see approach can be adopted to determine whether the allergy will resolve or the patient will receive an extended and unnecessary wheat elimination diet.

\section{Methods}

We enrolled 13 patients with a positive DBPCFC result to raw wheat flour from an original cohort of 27 patients (24 Italian and 3 Danish), all of whom had suspected wheat allergy, as previously described [4].

Patient characteristics and diagnostic challenge results are reported in the original study [4]. In brief, all of the patients reported a history of symptoms shortly after ingestion of wheat products. Patients were selected on the basis of their clinical history and positive results in skin tests or determination of specific IgE. Grass pollen allergy status was not a selection criterion. Clinical and laboratory assessments were performed. Specific IgE antibodies (CAP-FEIA, Pharmacia-Upjohn) to wheat, Pru p 3, and $\omega$-5-gliadin were determined according to the manufacturer's instructions. Immunoblotting of the 3 Osborne fractions (albumin/globulin, gliadins, and glutenins) of raw and cooked wheat was performed according to the manufacturer's instructions [15]. Tri a 14 was initially determined by immunoblotting and later by CAP when it became available. Antitransglutaminase antibodies were used to screen for celiac disease prior to DBPCFC.

The symptoms that manifested during the initial DBPCFC were typical of IgE-mediated reactions, with most involving the skin, mucosa, and gastrointestinal tract (urticaria in 8 patients, pruritus in 4, angioedema in 3, oral allergy syndrome in 5, and abdominal pain in 5); a smaller number of patients experienced respiratory manifestations (asthma in 3, persistent cough in 3 , and rhinitis in 1). Patients originally identified as wheat-allergic by DBPCFC were placed on a wheat-free diet and discharged with scheduled clinical follow-up visits at 6 months and at 1,3 , and 5 years. Wheat exposure was monitored to identify voluntary or inadvertent wheat ingestion and tolerance. In the case of cancelled visits, patients were interviewed by telephone at 12- to 24-month intervals. None of the patients underwent allergen immunotherapy.

Wheat allergy status was ascertained after a 5-year interval with a second wheat DBPCFC before retesting negative to antitransglutaminase antibodies. The second DBPCFC was carried out with raw wheat. Determination of specific IgE was also repeated after 5 years of wheat avoidance.

The challenge procedure is reported in the original paper [4]. In brief, the test meals were prepared by expert dieticians using wheat flour, potato starch, water, cocoa, partially cooked minced rice, sugar, and lemon aroma syrup; allergies to these foods were excluded prior to testing. Twentyfive grams of raw wheat flour was used in the active meal. Doses were administered at 20-minute intervals. A minimum starting dose of $100 \mathrm{mg}$ of raw wheat was administered, and doses were increased $(100 \mathrm{mg}, 500 \mathrm{mg}, 1 \mathrm{~g}, 1.5 \mathrm{~g}, 3 \mathrm{~g}, 6 \mathrm{~g}$, and $12 \mathrm{~g}$ ) until symptoms were reported/observed or until the entire test meal was eaten. 


\section{Results}

Ten Italian patients took part in the follow-up study, as 3 of the 13 selected patients were lost to follow-up (2 Danish and 1 Italian). Assessment of wheat allergy status revealed that most patients originally diagnosed as truly allergic to wheat [3] continued to avoid wheat after 5 years, even if the patient had accidentally ingested wheat without an allergic reaction.

The Table shows the demographic data, wheat-specific IgE, and grass sensitization status. The study population had a mean age of 40 years and comprised 7 females and 3 males. The mean period of wheat avoidance was 4.2 years. Most of the patients presented adult-onset food allergies, mainly to fruit and vegetables; 1 patient was also allergic to barley and rye, and 1 patient to rice and corn. As far as the sensitization pattern was concerned, most patients tested positive for $\alpha$-amylase inhibitors. Three patients were sensitized to Pru p 3 and Tri a 14, whereas only 1 patient was sensitized to $\omega$-5-gliadin and 1 to low-molecular-weight glutenin.

Patients 1, 2, and 3 had reintroduced wheat spontaneously after having avoided it for 18, 30, and 36 months, respectively. These 3 patients complained of mild gastrointestinal symptoms at reintroduction, although they maintained wheat in their diet. The patients did not undergo retesting with wheat DBPCFC.

Patients 4-10 continued to avoid wheat during the followup period and, while inadvertent ingestion of small amounts of wheat was reported, no relevant allergic manifestation had occurred. None of the patients developed new illnesses or new allergic conditions. Seven patients were tested again for wheat-specific IgE and wheat DBPCFC using raw wheat flour [patients 4-10]. The Table shows the clinical history for wheat challenge before and after wheat avoidance. Six of the 7 patients underwent a wheat DBPCFC and were instructed to introduce cooked wheat openly on a daily basis (25 $\mathrm{g}$ of cooked pasta or bread). Four of the 7 patients were sensitized to grass pollen. Patient 5 was the only patient to remain allergic to wheat (see Table for challenge symptoms). The patient was advised to continue on a wheat-free diet.

Nine of the 10 patients $(90 \%)$ with challenge-proven wheat allergy were confirmed to have reacquired wheat tolerance.

The exercise test was not carried out at the re-evaluation, since 1 patient, patient 3 , declined to undergo the stress test

Table. Demographic Data, Wheat-Specific IgE and Challenge Results Before and After Wheat Avoidance, and Grass Pollen Sensitization

\begin{tabular}{|c|c|c|c|c|c|c|c|c|c|c|c|}
\hline & Sex & Age $^{a}$ & $\begin{array}{c}\text { Wheat-Specific } \\
\text { IgE at } \\
\text { Diagnosis, } \\
\text { kU/L }\end{array}$ & $\begin{array}{c}\text { Wheat-Specific } \\
\text { IgE at } \\
\text { Re-evaluation, } \\
\mathrm{kU} / \mathrm{L}\end{array}$ & $\begin{array}{l}\text { Wheat } \\
\text { DBPCFC } \\
2004\end{array}$ & $\begin{array}{c}\text { Wheat } \\
\text { DBPCFC } \\
2009\end{array}$ & $\begin{array}{l}\text { Wheat } \\
\text { Status }\end{array}$ & $\begin{array}{c}\text { Wheat } \\
\text { Avoidance, } \\
\text { y }\end{array}$ & $\begin{array}{c}\text { Age of } \\
\text { Wheat } \\
\text { Tolerance, } \\
\text { y }\end{array}$ & $\begin{array}{l}\text { Grass } \\
\text { Pollen } \\
\text { Sensiti- } \\
\text { zation }\end{array}$ & $\begin{array}{c}\text { Pattern of } \\
\text { Sensitization }\end{array}$ \\
\hline $\mathrm{P} 1$ & $\mathrm{~F}$ & 54 & 1.4 & 0.53 & $\mathrm{AE}, \mathrm{GI}$ & NP & Tol & 1.5 & 55.5 & - & $\alpha-\mathrm{AI}$ \\
\hline $\mathrm{P} 2$ & $\mathrm{~F}$ & 16 & $>100$ & 20.8 & $\mathrm{AD}, \mathrm{U}, \mathrm{GI}, \mathrm{R}$ & NP & Tol & 2.3 & 18.3 & - & $\begin{array}{c}\omega / 5 \text {-gliadin } \\
\alpha-\mathrm{AI}\end{array}$ \\
\hline P3 & M & 42 & 17.2 & 5.7 & EIU, GI, AE & NP & Tol & 3 & 45 & - & $\begin{array}{c}\alpha-A I, \\
\text { LMW-glutenin }\end{array}$ \\
\hline P4 & M & 44 & 38.7 & 9.22 & A, GI, & Negative & Tol & 5 & 51 & - & $\begin{array}{l}\text { Tri a } 14, \\
\text { Pru p } 3\end{array}$ \\
\hline P5 & $\mathrm{F}$ & 50 & 6.3 & 2.49 & A, R, OAS P, & E, $\operatorname{Pr}$ & All & 5 & - & + & $\begin{array}{l}\text { Tri a 14, } \\
\text { Pru p } 3\end{array}$ \\
\hline P6 & $\mathrm{F}$ & 45 & $<0.35$ & $<0.1$ & V, GI, AE & Negative & Tol & 5 & 50 & - & $\alpha-\mathrm{AI}$ \\
\hline P7 & $\mathrm{F}$ & 37 & 1.97 & 0.23 & EIU & Negative & Tol & 5 & 42 & - & $\begin{array}{l}\text { Tri a 14, } \\
\text { Pru p3 }\end{array}$ \\
\hline P8 & $\mathrm{F}$ & 60 & 3.57 & 1.23 & OAS, U & Negative & Tol & 5 & 65 & + & $\alpha-A I$ \\
\hline P9 & M & 40 & 0.54 & 0.18 & A & Negative & Tol & 5 & 45 & + & $\alpha-\mathrm{AI}$ \\
\hline P10 & $\mathrm{F}$ & 28 & 0.89 & 0.48 & $\mathrm{U}$ & Negative & Tol & 5 & 33 & + & $\alpha-\mathrm{AI}$ \\
\hline
\end{tabular}

Abbreviations: $\alpha$-Al, $\alpha$-amylase inhibitor; $A$, asthma; $A D$, atopic dermatitis; $A E$, angioedema; All, allergic; $C$, cough; $E$, erythema; ElU, exercise-induced wheat urticaria; $\mathrm{H}$, headache; GI, abdominal colic; LMW, low-molecular-weight inhibitor; NP, not performed; OAS, oral allergy syndrome; Pr, pruritus; Tol, tolerant; U, urticaria; $\mathrm{V}$, vomiting.

${ }^{a}$ Age at diagnosis of wheat allergy.

Other food allergies detected in the study patients included tomato $(4,8,9)$, carrot $(8)$, fennel $(4)$, soy $(8)$, peach $(2,4,5)$, cherry $(2)$, grape $(4,5)$, melon (8), apple $(2,4)$, hazelnut $(2,8)$, chestnut $(5,8)$, barley and rye (4), and corn and rice (5).

The pattern of sensitization to wheat allergens was $\alpha$-amylase inhibitor in 7 patients, Tri a14 and Pru p 3 in 3 patients, and Tri a 19 or $\omega$-5-gliadin in 1 patient. The pattern of sensitization to other cereals was barley in 5 patients, rye in 5 patients, rice in 2 patients, and corn in 1 patient.

Pru $\mathrm{p} 3$ and $\omega$-5 gliadin were assessed using CAP, $\alpha$-amylase inhibitor and Tri a 14 by immunoblotting. The latter was subsequently confirmed by CAP (when it became available) with stocked sera. 
and patient 7 , who had passed the second wheat challenge, reported that she had performed strenuous exercise after the challenge without symptoms.

Wheat avoidance was associated with a reduction in wheatspecific IgE values compared with the values detected at the time of the initial diagnosis in all of the patients reviewed: median (IQR), $2.77(0.35-100) \mathrm{kU} / \mathrm{L}$ at the time of diagnosis and $0.88(0.1-20.8) \mathrm{kU} / \mathrm{L}$ after elimination. The magnitude of the reduction did not vary according to grass pollen sensitization. Wheat-specific IgE levels in these patients before and after reintroduction of wheat are shown in the Table.

Regardless of the fact that wheat-specific IgE had decreased in patient 5 ( 6.3 to $2.5 \mathrm{kU} / \mathrm{L}$ ), we found no change in the wheat dose delivered ( $25 \mathrm{~g})$ in either challenge, even if challenge symptoms were reported to be less severe when compared with the first wheat DBPCFC. Patient 5 was sensitized to Pru p 3 and grass pollen.

Tolerance was subsequently confirmed with an additional 7-year follow-up.

\section{Discussion}

Our main finding was that in a cohort of prospectively evaluated wheat-allergic adult patients, wheat allergy resolved in $90 \%$ of cases after a mean period of 4.2 years. We therefore conclude that adult-onset wheat allergy seems to be a transient form of food allergy with a very favorable prognosis.

We stress that all of the wheat-allergic patients described herein were diagnosed using DBPCFC with a standardized meal; all of the patients who developed wheat tolerance were of Italian origin and had taken part in a multicenter study [3]. Most of these patients had concomitant plant and food allergies and manifested true adult-onset wheat allergy inasmuch as they had always tolerated wheat and became allergic to this cereal at some point in adult life (mean age, 41.6 years).

Despite the frequency of wheat sensitization, wheat allergy in adults is rather uncommon, owing to its cross-reactivity with grass pollen. The most frequent form of clinical wheat allergy diagnosed in adults is WDEIA, in which wheat has a pivotal role for yet unknown reasons in both adults and children. Two of the patients in the present study also had exercise-induced wheat allergy (patients 3 and 7).

Several factors can exert an influence on the development of food allergy in adults. These include the use of antacids that alter protein digestion (which have been shown to play a key role in the development of allergy to fish and melon [9]), the use of nonsteroidal anti-inflammatory drugs that alter protein absorption in the gastrointestinal tract, and alcohol intake. As far as wheat is concerned, one can conjecture that the incomplete digestibility that distinguishes some wheat fractions, such as gliadins, may partially favor the development of wheat-related immunological disorders in the adult, such as eosinophilic esophagitis, where wheat seems to play a prevalent role [10].

Another possible explanation for the development of wheat allergy in patients with eczema could be the cutaneous sensitization generated by soaps that contain hydrolyzed wheat protein. Wheat sensitization via the skin after using soap bars that contain hydrolyzed wheat protein has recently been reported in Japan. Most patients had used a soap bar named "Cha-no-Shizuku" and experienced anaphylaxis or other allergic reactions in association with exercise and nonsteroidal anti-inflammatory drugs [11].

Indeed, wheat displays complex physicochemical properties. According to the Osborne classification, the various fractions of wheat proteins include water and salt-soluble proteins (ie, albumins and globulins, which are mainly responsible for baker's asthma) and alcohol and acid/alkali-soluble proteins (namely gliadins and glutenins, which are associated with WDEIA and wheat allergy). The most important wheat allergens are $\alpha$-amylase inhibitors, gliadins, and glutenins. Among gliadins, $\omega-5$ (Tri a 19) is implicated in WDEIA and food allergy. In the Mediterranean area, Tri a 14, a nonspecific lipid transfer protein (nsLTP), is implicated not only in wheat allergy and WDEIA, but also in baker's asthma [12]. Interestingly, in addition to the complex physicochemical features of wheat, several gliadin peptides that are rich in proline residues (such as the 33-mer peptide) have been shown to be particularly resistant to proteases and therefore undergo incomplete digestion in the gastrointestinal tract and retain their immunological features [13]. Most of the patients in the present cohort were sensitized to $\alpha$-amylase inhibitors. The remaining patients tested positive to Tri a 14, an LTP, or $\omega-5$ gliadin. One patient was cosensitized to both $\alpha$-amylase inhibitor and $\omega-5$ gliadin. Another patient was cosensitized to both $\alpha$-amylase inhibitor and low-molecularweight glutenin.

We therefore speculate that an atopic individual under the influence of additional risk factors, some of which are specified above, can become allergic to wheat, which is difficult to digest per se. These patients should be considered a distinct population set apart from the pediatric population.

As far as the prognosis of wheat allergy in children is concerned, available series evaluating the natural history of IgE-mediated allergy, including both prospective and retrospective analyses and challenges performed under clinical supervision or at home, show that wheat allergy is outgrown in most cases with an elimination diet after a median period of 6.5 years. Other favorable prognostic factors include a low wheat-specific IgE titer at the time of diagnosis, higher specific IgE levels at an early age, and the absence of $\operatorname{IgE}$ against gliadin $[5-6,8]$.

Prognostic factors in adult populations remain largely unknown. Despite the fact that all of the study patients showed a decrease in wheat-specific IgE levels, we could not identify a statistical correlation between a decrease in specific $\operatorname{IgE}$ levels and negative challenge result, likely owing to the small patient population, although it may reflect a unique feature of adults with wheat allergy. With the exception of patients 2, 3, and 4 , all patients who became wheat-tolerant continued to display wheat-specific IgE, albeit at low levels $(<3 \mathrm{kU} / \mathrm{L})$. This finding could be explained only partially by serological crossreactivity between wheat and grass pollen, inasmuch as only $40 \%$ of the patients were grass-sensitized (patients $5,8-10$ ), compared with $70 \%$ in the series of Nilsson et al [8]. Of note, patients $1-4,6$, and 7 showed no signs of grass sensitization 
and continued to have positive $\operatorname{IgE}$ for wheat, even after developing wheat tolerance. This finding may have several explanations. Knowledge of wheat allergen is still far from complete, and solutions adopted for commercial wheat skin prick tests display a mixture of the more common allergens without covering the entire spectrum. Besides, the nature of the epitopes recognized by the antibodies (conformational vs sequential) is different in adult patients who eventually tolerate wheat compared with those who do not outgrow the allergy, as is the case of allergy to milk and eggs [14]. In contrast, patient 5 continued to have clinical wheat allergy despite the decrease in wheat-specific IgE.

The sensitization pattern could also play a role. It is noteworthy that in our cohort, the only patient who did not overcome the allergy to wheat was positive to LTP (Tri a 14 and Pru p 3). However, the small number of patients prevents us from drawing definitive conclusions as far as the correlation between outcome and molecular sensitization is concerned.

Patients 3 and 7 had a history of wheat-dependent exerciseinduced urticaria, and both became wheat-tolerant. Patient 3 no longer manifested urticaria after wheat or after wheat ingestion and exercise; we advised the patient to undergo wheat and exercise challenge, although he declined, since symptoms were no longer present. However, the small number of patients with presumed exercise-induced urticaria prevents us from drawing definitive conclusions.

Of note, the 3 patients who spontaneously reintroduced wheat were not sensitized to grass pollen, whereas the only patient who maintained a wheat-allergic status was grass pollen-sensitive and allergic to peach LPT. The 3 patients who had spontaneously reintroduced wheat (patients 1-3) originally complained of gastrointestinal symptoms upon wheat challenge, compared with only 1 patient in the group of patients who continued to avoid wheat (patient 6). Thus, it may be that the presence of gastrointestinal symptoms at the time of diagnosis could serve as a prognostic marker of more rapid acquisition of tolerance, as has been reported in children [6].

In conclusion, we found that IgE-mediated wheat allergy had an excellent prognosis in a small population of Italian adults. Although wheat-specific IgE titers could not be used to estimate the likelihood of developing wheat tolerance, wheat-allergic adults should be re-evaluated periodically, since tolerance can be expected in the vast majority of patients after a variable period of wheat avoidance. Wheat allergy ceased in $90 \%$ of the Italian patients included in our cohort; therefore, adult-onset wheat allergy seems to be a transient form of food allergy with a very favorable prognosis. The robustness of this finding is further substantiated by the additional 7-year follow-up period, during which no relapses of wheat allergy were recorded.

Given that the mechanisms of natural tolerance to food allergens are largely unknown, further studies are needed.

\section{Funding}

The authors declare that no funding was received for the present study.

\section{Conflicts of Interest}

The authors declare that they have no conflicts of interest.

\section{References}

1. Mimura T, Noma H, Yamagami S. Conjunctival sensitization to hydrolysed wheat protein in facial soaps. J Invest Allergol Clin Immunol. 2014;34(2):122-41.

2. Venter C. Epidemiology of food allergy. Pediatric Clin North Am. 2011;58(2):327-49.

3. Nwaru BI, Nwaru BI, Hickstein L, Panesar SS, Roberts G, Muraro A, et al. EAACl Food Allergy and Anaphylaxis Guidelines Group. Prevalence of common food allergies in Europe Allergy: a systematic review and meta-analysis. Allergy. 2014;69(8):992-1007.

4. Scibilia J, Pastorello EA, Zisa G, Ottolenghi A, Bindslev-

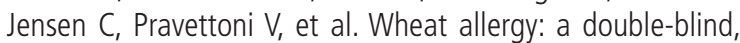
placebo-controlled study in adults. J Allergy Clin Immunol. 2006; 117(2):433-9.

5. Keet CA, Matsui EC, Dhillon G, Lenehan P, Paterakis M, Wood RA. The natural history of wheat allergy. Ann Allergy Asthma Immunol. 2009;102(5):410-5.

6. Rodriguez del Rio P, Diaz-Perales A, Sanchez-Garcia S, Escudero C, Do Santos P, Catarino M et al. Oral Immunotherapy in Children with IgE-mediated Wheat Allergy: outcome and molecular changes. J Invest Allergol Clin Immunol. 2014;24(4):240-8

7. Czaja-Bulsa G, Bulsa M. The natural history of IgE mediated wheat allergy in children with dominant gastrointestinal symptoms. Allergy Asthma Clin Immunol. 2014;10(1):12.

8. Nilsson N, Sjölander S, Baar A, Berthold M, Pahr S, Vrtala S, et al. Wheat allergy in children evaluated with challenge and $\mathrm{IgE}$ antibodies to wheat components. Pediatr Allergy Immunol. 2015;26(2):119-25.

9. Unteramayr $E$, Jensen-Jarolim $E$. The role of protein digestibility and antacids on food allergy outcomes. J Allergy Clin Immunol. 2008;121(6):1301-8.

10. Gonsalves N, Yang GY, Doerfler B, Ritz S, Ditto AM, Hirano L. Elimination diet effectively treats eosinophilic esophagitis in adults: food reintroduction identifies causative factors. Gastroenterology. 2012;142:1451-9.

11. Hiragun M, Ishii K, Yanasa Y, Hiragun T, Hide M. Remission rate of patients with wheat allergy sensitized to hydrolyzed wheat protein in facial soap. Allergol Int. 2016;65(1):109-11.

12. Pastorello EA, Farioli L, Stafylaraki C, Scibilia J, Mirone C, Pravettoni $V$, et al. Wheat dependent-exercise inducedanaphylaxis caused by a LTP and not by omega- 5 gliadin. Ann Allergy Asthma Immunol. 2014;112(4):386-7.

13. Janssen G, Christis C, Kooy-Winkelaar Y, Edens L, Smith D, van Veelen $P$, et al. Ineffective degradation of immunogenic gluten epitopes by currently available digestive enzyme supplements. PLoS One. 2015;10(6):e0128065.

14. Wang J, Lin J, Bardina L, Goldis M, Nowak-Wegrzyn A, Shreffler WG, et al. Correlation of lgE/lgG4 milk epitopes and affinity of milk-specific lgE antibodies with different phenotypes of 
clinical milk allergy. J Allergy Clin Immunol. 2010;125(3):695 702.

15. Pastorello EA, Farioli L, Conti A, Pravettoni V, Bonomi S, lametti SS, et al. Wheat IgE-mediated food allergy in European patients: alpha-amylase inhibitors, lipid transfer proteins and low-molecular-weight glutenins. Allergic molecules recognized by double-blind, placebo-controlled food challenge. Int Arch Allergy Immunol. 2007;144(1):10-22.
- Manuscript received May 11, 2018; accepted for publication July 24, 2018.

\section{- Elide Anna Pastorello}

Unit of Allergology and Immunology,

Dipartimento Medico Polispecialistico

ASST Grande Ospedale Metropolitano Niguarda

Milan, Italy

E-mail: elide.pastorello@ospedaleniguarda.it 